\title{
The Effects of Obesity and Bariatric Surgery on Fertility
}

\section{(Dibrahim ÇOLHAN, ${ }^{a}$ \\ (1) Erkan ERDEM, ${ }^{\text {b }}$ \\ (1)Akın USTA, \\ - Meriç KARACAN ${ }^{d}$}

\author{
Clinics of \\ ${ }^{\mathrm{a}}$ General Surgery, \\ bUrology, \\ dIVF Unit, \\ Ota-Jinemed Hospital, \\ İstanbul \\ 'Department of Gynecology and Obstetrics, \\ Balıkesir University Faculty of Medicine, \\ Balıkesir \\ Received: 14.03 .2017 \\ Accepted: 15.06 .2017 \\ Available online: 31.08 .2018 \\ Correspondence: \\ Akın USTA \\ Ota-Jinemed Hospital, Clinic of IVF Unit, \\ İstanbul, TURKEY \\ drakinusta@gmail.com
}

\begin{abstract}
The prevalence of obesity, one of the most common health problems in the world, has shown an increase in the recent years. Obesity has detrimental effects on the reproductive system. Furthermore, infertility is more common in obese patients. Weight loss has been found to have positive effects on the reproductive system of these patients. Although the reason is not clearly known, a decrease in the amount of fat, affects fertility in a positive way, as a consequence of normalization of the hormonal balance and sexual activity. Among the weight-loss strategies, caloric restrictions and exercise constitute the first step. However, certain surgical procedures called bariatric surgeries are also performed on some obese patients, for contributing to weight loss. Till date, many bariatric surgical procedures have been defined, which can be classified as malabsorptive, restrictive, and combined procedures. The effect of various surgical techniques on the fertility in patients treated with bariatric surgery is still controversial. A multicentric study had stated that there is no difference between restrictive and malabsorptive bariatric surgery techniques. Obesity has been shown to have serious potential effects on the male and female fertility factors. Semen parameters investigated as factors associated with obesity include, sperm concentration, number and motility. In some recent studies, it has been reported that increased BMI could lead to infertility by disrupting the hormonal profile and/or causing DNA damage in the sperm. Studies have also reported that obese men treated with bariatric surgery showed significantly decreased estrogen levels, while having appreciably increased testosterone, SHBG and FSH levels, and improved sexual functions. To conclude, obesity is a factor that reduces the fertility potential in both, men and women. While dealing with obesity, dietary habits should be regulated and physical activity should be increased at first. Bariatric surgery should be discussed in cases where all other comprehensive measures have failed to yield any results.
\end{abstract}

Keywords: Obesity; infertility; bariatric surgery

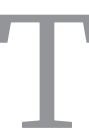
he World Health Organization (WHO) has defined obesity as "an abnormal or excessive fat accumulation in the body that may impair health". It is increasing speedily, worldwide.

Several disorders such as coronary system diseases, endocrine disorders, respiratory system diseases (sleep apnea, chronic obstructive pulmonary disease), digestive system diseases (hepatosteatosis, gallbladder diseases, reflux esophagitis), and genitourinary system disorders (erectile dysfunction, reproductive dysfunction) are caused due to excessive adipose tissue deposition. In addition, obese women are at a higher risk of developing colorectal cancer, endometrial cancer and postmenopausal breast cancer, as compared to the non-obese women.

Infertility is the inability to become pregnant even after having regular intercourse without birth control for a period of one year. Etiological 
studies have revealed a correlation between obesity and infertility, based on the hormonal and epigenetic causes.

The treatment of obesity, starting with dietary and exercise regulations and performing obesity surgery, i.e., bariatric surgery in cases non-responsive to treatment, will help fight against other health problems. Bariatric surgery has become one of the commonly performed surgical procedures, especially in the last decade, in developed countries as well as in Turkey. This review aimed at evaluating the effects of obesity on male and female fertility, as well as the effects of bariatric surgery in this regard.

\section{METHODOLOGY}

The articles with full texts and/or abstracts published between 01.01.2004 and 10.01.2017, found by conducting English and Turkish literature search through PubMed, were compiled. The keywords used included, bariatric surgery and female infertility, bariatric surgery and male infertility, obesity and infertility, the effect of obesity on male infertility, the effect of obesity on female infertility, and reproductive pathologies.

\section{THE EFFECT OF OBESITY ON FEMALE FERTILITY}

In the definition of obesity, the classification proposed by the World Health Organization is used most commonly. According to that classification, individuals having a Body Mass Index (BMI: $\mathrm{kg} / \mathrm{m}^{2}$ ) of 25-30 are considered overweight, those having a BMI of 30-35 are considered obese, those having a BMI of 35-40 are considered severely obese, and those having a BMI over 40 are considered morbidly obese. In another classification, waist circumference is taken as a criterion, and it is stated that females having a waist circumference over 80 $\mathrm{cm}$, and males having waist circumference over 90 $\mathrm{cm}$ have excessive visceral fat.

In a study conducted in 2008, approximately $1 / 3$ of adult women living in the United States, and 23\% of Europeans were reported to be obese. ${ }^{1}$ According to the 2014 data released by Turkish Health Technology Assessment Department, the obesity rate in Turkey which was 12\% in 2003 raised to $15.2 \%$ in $2008,16.9 \%$ in $2010,17.2 \%$ in 2012, and $19.9 \%$ in 2014, respectively.

An obese woman loses approximately 7.1 years of her life. A sedentary lifestyle and a high-calorie diet have unfortunately been increasing the risk of obesity in recent years. Obesity is a multifactorial issue. Therefore, it is insensible to explain its cause as just not wanting to lose weight, non-compliance with diet, or sedentary lifestyle.

Obesity can affect conception and the subsequent pregnancy adversely. ${ }^{2}$ The risk of infertility in obese women is about three times higher as compared to that in women with a normal BMI. The mechanisms, by which obesity causes infertility, are still an area of debate. The topics being investigated include the data that obesity disrupts ovulation, affects oocyte development adversely, affects the development of embryo or endometrium, and increases the risk of abortion.

The prevalence of obesity is higher in females than in the males. The lower metabolic rate in females than that in males is an important cause of the higher obesity prevalence in females. In addition, cessation of ovulation in postmenopausal period, as well as the fact that the metabolic rate no longer increases in the luteal phase, makes women more prone to weight gain. ${ }^{3}$ Since the basal metabolic rate decreases decennially by $2 \%$ after the age of 18 , an individual who does not exercise and does not restrict their caloric intake after 30 years of age will inevitably gain weight.

Adipose tissue performs three tasks: energy storage, formation of a protective zone against trauma, and regulation of body temperature. A close although complex correlation is known to exist between energy metabolism, mechanism of food intake and the reproductive system. Corticotropin-Releasing Hormone (CRH), oxytocin, neurotensin, and Cyclo His-Pro (CHP) arising after $\mathrm{TRH}$ proteolysis are appetite reducing neuropeptides.

The hormones, leptin and ghrelin, play a role in the organization of this relationship. Leptin is produced in adipose tissue. The term 'leptin' has been derived from the Greek word leptos. It circu- 
lates in the blood in free form along with a form in which it is bound to proteins, and affects the food intake as well as energy balance in the central nervous system. Leptin levels fall in people with reduced adipose tissue. This decrease stimulates caloric intake in order to prevent the reproductive function from getting damaged, and also reduces energy consumption, thereby resulting in a decreased secretion of gonadotropins. ${ }^{4}$

Ghrelin is mostly secreted from the upper region of the stomach and the intestines, and acts on the hypothalamic centre providing energy balance. Ghrelin levels in obese individuals decreases; although, it raises and stimulates appetite during hunger. Ghrelin is affected by glucose levels, whereas leptin is affected by fat masses. The relationship between energy and fat metabolism, and the reproductive system is provided through the leptin-ghrelin system. ${ }^{5}$ Of the $90-95 \%$ individuals who lose weight rapidly, regain it again. The root cause of this is the increased appetite and decreased energy consumption experienced once the leptinghrelin levels turn back to their previous levels, after a long-term stabilization. A $10 \%$ reduction in weight leads to a 53\% decrease in the leptin level. Therefore, it is necessary to increase physical activity and comply with the diet for being able to keep weight loss at the same level until a new hormonal balance is established.

Adiponectin is another hormone secreted by the adipose tissue and is effective in insulin resistance and fatty acid metabolism. It has a stimulating effect on weight loss and assists leptin in accomplishing its effect in the brain.

Whether obesity develops as a result of increase in the number of fat cells or it is due to the swelling and growth of the cells is a controversial topic. In obese individuals, the volume of fat cells has been found to increase three times. On the other hand, an increase in the number of fat cells is observed only in obese people. Obesity due to an increase in the number of fat cells (hyperplastic obesity) is associated with intrauterine, childhood and adolescence periods, and weight loss for such obese populace is more difficult than that for individuals with hypertrophic (fat cell growth) type of obesity. Studies conducted on identical twins reported that $30 \%$ of the total weight of an individual is attributable to genetic factors and $70 \%$ to environmental factors. ${ }^{6}$

Gynecoid obesity is defined as excessive fat deposition in the femoral-gluteal region (pear shape), while android obesity is defined as excessive fat deposition in the abdominal wall at the center and visceral mesentery (apple shape). The fat in the gynecoidal regions especially is indicative of the amount of stored fat and its mobilization is more difficult. However, as compared to android obesity, it is less associated with diabetes and coronary heart disease since it results in minimal fatty acid excretion. The fat in the android regions is metabolically more active and sends triglycerides to other tissues to meet the energy requirements. In such people, hyperinsulinemia, elevated androgen levels, hypertension, and increased risk of cardiovascular disease (usually android type fat deposition is seen in adolescents) are observed. In people with android type of obesity, loss of weight directly reduces the mentioned risks.

\section{Obesity and Hormonal Changes}

Adipose tissue is metabolically active. Androgen turns into estrogen, estradiol turns into estrone and DHEA turns into androstenediol. ${ }^{7}$ The level of SHBG (sex hormone-binding globulin) is lower in obese females; it was found to be even further lower, especially in women with central obesity. In this way, free androgen levels and their metabolic clearance rates rise, and stimulate the production of androgens again. One of the root causes of anovulation seen in obese females is this hyperandrogenemic condition. Weight loss causes a rapid decline in androgen levels.

It also contributes to an increase in the androgen levels in obese individuals by causing a decrease in hyperinsulinemia and SHBG, and stimulating LH through insulin and insulin-like growth factor-1 (IGF-1) receptors in the ovary.

\section{Obesity and Epigenetic Changes}

The occurrence of mitotic and/or meiotic changes in gene expression, without any changes in the 
DNA sequence, is referred to as 'epigenetic changes'. Obesity can lead to epigenetic changes in somatic cells and germ cells by causing chronic inflammation and oxidative stress, and affecting the hypermethylation of genes, histone modification, and microRNAs. ${ }^{8}$ This can be related to the increase in various types of cancer and the development of atherosclerosis, neurological diseases and inflammatory diseases. Alterations in germ cells can be transferred to the next generations, and may pose health problems in children born in the future generations.

\section{Obesity and Anovulation}

Obesity has been alleged to cause anovulation by affecting the hypothalamo-hypophyseal axis adversely. Obese women were found to have menstrual disorders at a rate of 3.1 times more frequently than women in the normal weight range. In addition, fecundity was found to be decreased even in obese patients having normal menstrual cycles. ${ }^{9}$ In studies, anovulation related infertility was observed to be $30 \%$ higher in women with a BMI in the range of 24 and 31, as compared to that in women with a BMI lower than 24 . This rate was reported to be even higher in females having a BMI over $31 .{ }^{10}$ Obese females have reduced amplitude of $\mathrm{LH}$ and show reduced excretion of progesterone metabolites. This condition can result in infertility by having an adverse effect on oocyte quality and the function of the corpus luteum.

The frequency of sexual intercourse was found to be lower in obese women than in women in the normal weight range. ${ }^{11}$ This is a factor affecting the chances of becoming pregnant. It has been stressed that decreased dopamine and increased serotonin activity in the brain, related to overeating, affect sexual desire. Consumption of excess amount of fat and sugar chronically reverses sexual desire into the desire to eat.

Polycystic ovary syndrome (PCOS) is characterized by the presence of oligomenorrhea, hyperandrogenism, and polycystic ovary seen during an ultrasonography. Approximately 3-50\% of women with PCOS are obese. Clinical and hormonal find- ings of PCOS are closely associated with the severity of obesity.

\section{Obesity and Oocyte}

In obese women, the gonadotropin dose used in IVF cycles was found to be higher, whereas the resultant number of oocytes was found to be lower. ${ }^{12}$ Low intrafollicular hCG concentrations were reported to be a cause of the lower number of mature oocytes in obese individuals. ${ }^{13}$ However, this has not been verified in other studies. ${ }^{14}$ Likewise, although fertilization rates in oocytes collected from obese women were found to be lower in some studies, other studies found no difference between the fertilization rates of oocytes collected from obese women and women with normal weight.$^{14,15,16}$

Abortion rates in obese women are also a controversial topic. In some studies, abortion rates in obese women were found to be lower due to problems in oocytes. ${ }^{17}$

\section{Obesity and Endometrium}

The possibilities that hyperestrogenic environment and insulin resistance in obese people could impair the development of endometrium, or that gene expression of endometrium could be different in obese people, are also emphasized. A study investigating the implantation potential of the endometrium in obese and non-obese females, who became pregnant with donor oocytes, showed that obesity alone did not affect the endometrium and implantation. ${ }^{18}$

\section{Obesity and Abortion}

In obese women, the abortion rate is reported to be higher (1.5-2.5 times) in pregnancies achieved through both, natural conception and with in-vitro fertilization (IVF). ${ }^{19}$ The increase in abortion rates is believed to be mainly due to oocyte quality.

\section{Obesity and Embryo}

The effects of obesity on the quality and number of embryos, as well as the presence of embryos that can be frozen, have also been the subjects of research. Although some studies have shown that obesity decreases the quality of oocyte and, conse- 
quently, embryo quality and the number of embryos that can be frozen, there is no consensus on this issue. ${ }^{12,14}$ It has also been asserted that the use of high-dose gonadotropin in obese women may affect oocyte quality and embryo quality, depending on the resistance to gonadotropins. ${ }^{20}$

\section{IVF and Obesity}

There are publications showing that obesity is associated with prolonged duration of ovulation induction in IVF procedures; increased dose of gonadotropin used for ovulation induction; disrupted synchronization in follicular growth; difficulty in vaginal ultrasonographic imaging, follicle aspiration, and embryo transfer due to excess amount of adipose tissue; excessive number of interrupted cycles; weak ovarian response; low follicular hCG concentration; inadequate number of embryos that can be frozen; decreased rates of pregnancy; and increased rates of abortion. ${ }^{14,17,19,20}$

\section{Fertility and Weight Loss}

It has been reported that weight loss normalizes menstruations in obese women, and even a 5\% loss of body weight provides an increase in fertility and improves hormonal abnormalities considerably. ${ }^{21}$

\section{The Effect of Obesity on Male Infertility}

Male factor alone is a cause in $20 \%$ of the infertile couples, whereas both male and female factors are present in $30-40 \%$ of the couples. Thus, male factor is seen in about half of the couples. The known factors related to male infertility include undescended testis, testicular torsion or trauma, varicocele, seminal duct infections, antisperm antibodies, hypogonadotropic hypogonadism, gonadal dysgenesis, and obstruction of the reproductive tracts. In some recent studies, it has been reported that increase in BMI may result in infertility by disrupting the hormonal profile and/or causing DNA damage to the sperm. ${ }^{22,23}$

\section{Obesity in Men and Hormonal Changes}

Spermatogenesis is a very complex phenomenon that lasts from the beginning of puberty till death. The Leydig and Sertoli cells in the hypothalamus, pituitary and testes regulate this process. The testicular functions are basically regulated by FSH and LH secreted from the pituitary gland, and are controlled by GnRH. An increased BMI in men has been found to be associated with SHBG, testosterone, inhibin B, and FSH levels. ${ }^{24}$ A meta-analysis reported that testosterone and SHBG levels were low in men having a high BMI. $^{25}$

\section{Obesity and Sperm Parameters}

In a study conducted by Jensen et al., 1,558 volunteers were examined. The sperm concentrations and total sperm counts in $22 \%$ of the participants with a BMI $>25$ were found to be lower than that in those with a normal BMI. Again, the prevalence of oligozoospermia was found to be $21.7 \%$ in men with a normal BMI, whereas it was $24.4 \%$ in men with a BMI $>25 .{ }^{26}$ Sperm motility is another semen parameter investigated as a parameter related to obesity. In another study, the sperm motility was $57.50 \%$ and $13.25 \%$ in obese fertile and obese infertile groups, respectively. ${ }^{22}$ The study revealed a negative correlation between BMI and sperm motility, in addition to the correlation between $\mathrm{BMI}$ and sperm concentration. Fejes et al. revealed a correlation between waist circumference and the total number of motile sperms, and between waist circumference and fast forward movement. ${ }^{27} \mathrm{Mar}-$ tini et al. examined 794 men classified into groups according to their BMIs, and found a negative correlation between BMI and total motility, and between BMI and advanced motility. ${ }^{28}$

However, the literature also reports studies that show no correlation between sperm count and obesity. ${ }^{23,} 29$ One such study conducted on a large number of subjects reported that there is no significant correlation between BMI and sperm concentration..$^{30}$

\section{Male Obesity and DNA Damage}

Sperm DNA integrity is important in terms of fertilization success and normal embryonic development. Two studies investigating the correlation between obesity and DNA damage reported that increased BMI can cause DNA damage in the sperm. $^{22,23}$ 
In addition, some syndromes that emerge as a result of genetic defects in men may cause both obesity and impaired spermatogenesis (e.g., Alström syndrome, Prader-Willi syndrome, and Angelman syndrome). ${ }^{31}$

The results are contradictory due to the low number of controlled animal model studies on the effect of obesity on fertility, inadequacy in the number of subjects included in studies, and the effects of influencing factors such as smoking.

\section{Obesity and Male Sexual Health}

Erectile Dysfunction (ED) is defined as a condition in which the patient is unable to achieve an erection firm enough for satisfactory sexual intercourse for a period of at least six months. ${ }^{32}$ In our country, the prevalence of ED was found to be $69.2 \%$ in a community-based study on the prevalence of ED and its correlations, conducted by the Turkish Andrology Association. ${ }^{33}$

In a study investigating the correlation between BMI and ED, which involved the examination of 1,339 subjects, obese individuals were found to be at about two times greater risk of ED as compared to individuals in the normal weight range (in $79 \%$ of those with BMI> 25). ${ }^{34}$ In another study, a total of 3,941 adult males aged 20 years and above were examined, and obese patients having a high waist circumference were found to be at a $50 \%$ greater risk of ED, as compared to those with a normal BMI. ${ }^{35}$

\section{THE EFFECT OF BARIATRIC SURGERY ON INFERTILITY}

The word 'bariatric' consists of the combination of the Greek word "baros" meaning "weight" and the Latin word "iatrikos/iatros," meaning "healing”. In individuals who are unable to lose weight with diet and lifestyle changes, bariatric surgery can be considered as an option. Although the reason has not been clearly revealed, a decrease in the amount of fat in men and women positively affects fertility, in consequence of the normalization of the hormonal/paracrine balance and sexual activity. ${ }^{36}$

Although there is no definitive consensus in this regard, candidates eligible for bariatric surgery include:

- Individuals having a BMI $\geq 40$

- Individuals having a BMI $\geq 35$ and comorbidity (type 2 diabetes, hypertension, sleep apnea syndrome and/or other respiratory diseases, nonalcoholic fatty liver disease, osteoarthritis, lipid abnormalities, gastrointestinal diseases and heart disorders).

- Patients who could not lose weight permanently, despite the previous professional trials.

Individuals having an acceptable risk for surgery. ${ }^{37}$

The search for surgical procedures against obesity started about 50 years ago, when obesity was not common like it is today. People tried to achieve healthy and permanent weight loss by using initially the malabsorptive technique, then the restrictive technique and in the later periods, the combination of both the techniques. Various procedures performed are shown below (Table 1).

Among all the techniques mentioned in the table, sleeve gastrectomy is becoming more common now-a-days, because of its positive properties. Intragastric balloon is a non-invasive, endoscopic endoluminal approach described by Nieben in 1982. As a material occupies a place in the stom-

\begin{tabular}{|c|c|c|}
\hline Malabsorptive procedures & Restrictive procedures & Combined procedures \\
\hline I Biliopancreatic diversion & — Vertical band gastroplasty & - Gastric bypass surgery (Roux-Y-bypass) \\
\hline \multirow[t]{4}{*}{ - Jejunoileal bypass } & - Adjustable gastric band & - Single-Anastomosis Duodeno-lleal bypass with Sleeve gastrectomy (SADI-S) \\
\hline & - Sleeve gastrectomy & \\
\hline & = Intragastric balloon & \\
\hline & — Gastric plication & \\
\hline
\end{tabular}


ach, it provides the sense of early satiety. Some of its models can also allow for refilling without the need to remove them from the stomach. ${ }^{38}$

\section{Effects of Bariatric Surgery on Female Infertility}

Since about $43 \%$ of the females who have undergone bariatric surgery are between 18 and 44 years of age (i.e., in the fertility period), collaborative works between gynecologists, endocrinologists and general surgeons dealing with obesity is desired. ${ }^{39}$ The literature reports many different studies stating that favorable results may be achieved after bariatric surgery. After bariatric surgery, menstrual cycles have been found to be recovered in more than $50 \%$ of the females. ${ }^{36}$

In a retrospective study, $62.7 \%$ of the 110 obese and infertile women were found to achieve a successful and uncomplicated pregnancy after bariatric surgery..$^{40} \mathrm{~A}$ meta-analysis of eight different studies, which enrolled 589 infertile women who had undergone obesity surgery, reported successful pregnancies in the ratio between $22 \%$ and $92 \% .{ }^{41}$

A study showed that insulin resistance decreased after RYGB (Roux En-Y gastric bypass), SHBG doubled after 12 months (on average), total and free androgens and DHEA decreased by $50 \%$, and after that they permanently remained at appropriate levels. ${ }^{42}$ In the same study, one year after the surgery, it was found that menstrual irregularity disappeared and regular menstrual cycles started in $85 \%$ of the women. In addition, these women were observed to be less likely to experience pregnancy-associated hypertension and gestational diabetes; were at a lower risk of getting a Large-for-Gestational-Age (LGA) infant; and at a higher risk of getting a Small-for-Gestational-Age (SGA) infant, as compared to women who did not undergo surgery. In patients treated with BPD (biliopancreatic diversion), high SGA ratios have been reported in pregnancies postoperatively. ${ }^{43,44,45}$

The rate of gestational diabetes also seems to be lower in women treated with bariatric surgery, as compared to those who did not undergo bariatric surgery. ${ }^{46,47}$ The main reason why surgery is such an effective method is the significant decrease in insulin resistance that occurs after bariatric surgery. ${ }^{48}$
One of the topics investigated in the postbariatric period is the effects of the surgery on vitamin and mineral levels. In a study, a decrease was detected postoperatively in the levels of iron, vitamin B12, vitamin D and zinc. ${ }^{49}$

Another study investigating the possible postoperative complications of bariatric surgery reported an increase in the premature births and spontaneous abortion rates in pregnancies achieved in the early periods. ${ }^{50}$ These effects were observed to be closely correlated to the postoperative period, especially that in which the pregnancy was achieved. Since there may be metabolic imbalances due to malabsorption in the first 12-18 months, when postoperative weight loss is most commonly experienced, patients are recommended to live this period without getting pregnant. ${ }^{44}$

Whether or not the surgical technique used creates a difference in the effect of bariatric surgery on infertility is a matter of debate, as well. In a multicentric study, it was stated that there is no difference between restrictive and malabsorptive bariatric surgery techniques. ${ }^{39}$ However, in the same study, the possibility of SGA infants was found to be higher after a malabsorptive method such as BPD (Biliopancreatic Diversion), and therefore, it was proposed to be considered as a high-risk. In another study, comprising of 219 patients between 18 and 45 years of age, which involved the comparison of the RYGB and adjustable gastric band (AGB) techniques, the rate of live births in RYGB was found to be lower than that in AGB. ${ }^{51}$

\section{Effects of Bariatric Surgery on Male Infertility}

The literature quotes a few studies relating to the effects of bariatric surgery on male infertility. A study conducted by Hammoud et al. reported that the serum estradiol levels dropped after bariatric surgery, while the testosterone levels elevated and adipokines were regulated..$^{25}$ The study conducted by Bastounis et al. reported that obese males who underwent vertical banded gastroplasty showed significantly decreased estrogen levels, while having significantly increased testosterone, SHBG and FSH levels, and improved sexual functions. ${ }^{52}$ 
Obesity has also been shown to have potentially serious effects on male fertility factor. After sleeve gastrectomy, significant changes were observed in serum testosterone levels and semen parameters of patients, who previously had azoospermia and oligospermia..$^{53}$

Another study reported no change in the semen parameters and sexual functions, while reporting elevated SHBG and testosterone levels, after RYGB. It was asserted that bariatric surgery may improve male reproductive function by reversing hypogonadism. ${ }^{54}$

However, in a study conducted by Di Frega et al., six previously healthy males became azoospermic after RYGB. Despite the normal hormone levels, spermatogenetic arrest was detected in the testicle..$^{55}$ Therefore, it should also be considered that uncontrolled weight loss may have adverse effects.

\section{Complications of Bariatric Surgery}

They can be considered as early and late-period complications or major and minor complications. High BMI and respiratory insufficiency are the most important risk factors that increase the risk of mortality. Complications of bariatric surgery are shown in Table 2.

In a meta-analysis involving the investigation of 161,576 patients between 2003 and 2012, mortality rate related to the surgery was found to be relatively low, while the perioperative mortality and postoperative mortality were $0.08 \%$ and $0.31 \%$, respectively. ${ }^{56}$ The most common causes of mortality were identified as pulmonary embolism, anastomosis, or leakage from stapler line and myocardial infarction.

In another meta-analysis that enrolled 2,834 patients, a leakage rate of $1.5 \%$ was reported after sleeve gastrectomy; leakages were detected most frequently between the third and 14 th postoperative days in the middle period.$^{57}$

In another study that enrolled 15,275 patients from 25 hospitals in the United States, the incidence rate of one or more complications was found to be $7.3 \% .{ }^{58}$ In the same study, the rates of life-threatening complications were defined in order of their fre-

\begin{tabular}{|c|c|}
\hline \multicolumn{2}{|c|}{ TABLE 2: Complications of bariatric surgery. } \\
\hline $\begin{array}{l}\text { Early period complications } \\
\text { — Bleeding } \\
\text { — Leakage } \\
\text { — Thromboembolism } \\
\text { — Intestinal obstruction } \\
\text { = Wound infection } \\
\text { — Mortality }\end{array}$ & $\begin{array}{l}\text { Late period complications } \\
\text { — Stenosis } \\
\text { — Intestinal obstruction } \\
\text { - Bleeding } \\
\text { — Vitamin and mineral deficiency }\end{array}$ \\
\hline
\end{tabular}

quency as follows: gastric bypasses (3.1\%), sleeve gastrectomy (2.2\%) and, adjustable comparison of the RYGB and adjustable gastric band $(0.78 \%)$.

The consensus in studies is that bariatric surgery is a reliable surgical procedure having low mortality and morbidity rates for eligible candidates.

\section{CONCLUSION}

Obesity is a factor that reduces the fertility potential in both males and females. Obesity must be struggled with by first regulating dietary habits and increasing physical activity. Bariatric surgery should be discussed in cases where no result could be achieved by comprehensive means.

\section{Source of Finance}

During this study, no financial or spiritual support was received neither from any pharmaceutical company that has a direct connection with the research subject, nor from a company that provides or produces medical instruments and materials which may negatively affect the evaluation process of this study.

\section{Conflict of Interest}

No conflicts of interest between the authors and / or family members of the scientific and medical committee members or members of the potential conflicts of interest, counseling, expertise, working conditions, share holding and similar situations in any firm.

\section{Authorship Contributions}

Idea/Concept: Meriç Karacan, İbrahim Çolhan; Desing: Erkan Erdem, Akın Usta, Meriç Karacan; Control/Supervision: Meriç Karacan; Data Collection and/or Processing: Erkan Erdem, İbrahim Çolhan; Analysis and/or Interpretation: Meriç Karacan, Akın Usta; Literature Review: Meriç Karacan, Akın Usta; Writing the Article: Ibrahim Çolhan, Erkan Erdem; Critical Review: Meriç Karacan, Akın Usta 


\section{REFERENCES}

1. Flegal KM, Carroll MD, Kit BK, Ogden CL. Prevalence of obesity and trends in the distribution of body mass index among US adults, 1999-2010. JAMA 2012;307(5):491-7.

2. Catalano PM, Shankar K. Obesity and pregnancy: mechanisms of short term and long term adverse consequences for mother and child. BMJ 2017;356:j1.

3. Van Pelt RE, Jones PP, Davy KP, Desouza CA, Tanaka H, Davy BM, et al. Regular exercise and the age-related decline in resting metabolic rate in women. $\mathrm{J}$ Clin Endocrinol Metab 1997;82(10):3208-12.

4. Catteau $A$, Caillon $H$, Barrière $P$, Denis $M G$, Masson D, Fréour T. Leptin and its potential interest in assisted reproduction cycles. Hum Reprod Update 2016;22(3).

5. Tena-Sempere M. Ghrelin as a pleotrophic modulator of gonadal function and reproduction. Nat Clin Pract Endocrinol Metab 2008;4(12):666-74.

6. Stunkard AJ, Harris JR, Pedersen NL, McClearn GE. The body-mass index of twins who have been reared apart. $\mathrm{N}$ Engl $\mathrm{J}$ Med 1990;322(21):1483-7.

7. Fritz MA, Speroff L. Obesity. Clinical Gynecologic Endocrinology and Infertility. 8th ed. Philadelphia: Lippincott Williams \& Wilkins; 2011. p.864-85.

8. Pembrey M, Saffery R, Bygren LO; Network in Epigenetic Epidemiology. Human transgenerational responses to early-life experience: potential impact on development, health and biomedical research. J Med Genet 2014;51(9):563-72.

9. Brewer CJ, Balen AH. The adverse effects of obesity on conception and implantation. Reproduction 2010;140(3):347-64.

10. Gesink Law DC, Maclehose RF, Longnecker MP. Obesity and time to pregnancy. Hum Reprod 2007;22(2):414-20.

11. Brody S. Slimness is associated with greater intercourse and lesser masturbation frequency. $J$ Sex Marital Ther 2004;30(4):251-61.

12. Esinler I, Bozdag G, Yarali H. Impact of isolated obesity on ICSI outcome. Reprod Biomed Online 2008;17(4):583-7.

13. Carrell DT, Jones KP, Peterson CM, Aoki V, Emery BR, Campbell BR. Body mass index is inversely related to intrafollicular HCG concentrations, embryo quality and IVF outcome. Reprod Biomed Online 2001;3(2):109-11.

14. Bellver J, Ayllón Y, Ferrando M, Melo M, Goyri E, Pellicer $A$, et al. Female obesity impairs in vitro fertilization outcome without affecting embryo quality. Fertil Steril 2010;93(2):447-54.

15. van Swieten EC, van der Leeuw-Harmsen $L$, Badings EA, van der Linden PJ. Obesity and
Clomiphene Challenge Test as predictors of outcome of in vitro fertilization and intracytoplasmic sperm injection. Gynecol Obstet Invest 2005;59(4):220-4.

16. Dokras A, Baredziak L, Blaine J, Syrop C, VanVoorhis BJ, Sparks A. Obstetric outcomes after in vitro fertilization in obese and morbidly obese women. Obstet Gynecol 2006;108(1): 61-9.

17. Robker RL. Evidence that obesity alters the quality of oocytes and embryos. Pathophysiology 2008;15(2):115-21.

18. Styne-Gross A, Elkind-Hirsch K, Scott RT Jr. Obesity does not impact implantation rates or pregnancy outcome in women attempting conception through oocyte donation. Fertil Steril 2005;83(6):1629-34.

19. Metwally M, Ong KJ, Ledger WL, Li TC. Does high body mass index increase the risk of miscarriage after spontaneous and assisted conception? A meta-analysis of the evidence. Fertil Steril 2008;90(3):714-26.

20. Tamer Erel C, Senturk LM. The impact of body mass index on assisted reproduction. Curr Opin Obstet Gynecol 2009;21(3):228-35.

21. Tang T, Glanville J, Hayden CJ, White D, Barth JH, Balen AH. Combined lifestyle modification and metformin in obese patients with polycystic ovary syndrome. A randomized, placebo-controlled, double-blind multicentre study. Hum Reprod 2006;21(1):80-9.

22. Chavarro JE, Toth TL, Wright DL, Meeker JD, Hauser R. Body mass index in relation to semen quality, sperm DNA integrity, and serum reproductive hormone levels among men attending an infertility clinic. Fertil Steril 2010;93(7):2222-31.

23. Villamor E, Msamanga G, Urassa W, Petraro $\mathrm{P}$, Spiegelman D, Hunter DJ, et al. Trends in obesity, underweight, and wasting among women attending prenatal clinics in urban Tanzania, 1995-2004. Am J Clin Nutr 2006;83(6):1387-94.

24. Pauli EM, Legro RS, Demers LM, Kunselman AR, Dodson WC, Lee PA. Diminished paternity and gonadal function with increasing obesity in men. Fertil Steril 2008;90(2):346-51.

25. Hammoud A, Gibson M, Hunt SC, Adams TD, Carrell DT, Kolotkin RL, et al. Effect of Rouxen-Y gastric bypass surgery on the sex steroids and quality of life in obese men. J Clin Endocrinol Metab 2009;94 (4):1329-32.

26. Jensen TK, Andersson AM, Jørgensen N, Andersen AG, Carlsen E, Petersen JH, et al. Body mass index in relation to semen quality and reproductive hormones among 1,558 Danish men. Fertil Steril 2004;82(4):863-70.

27. Fejes I, Koloszár S, Závaczki Z, Daru J, Szöllösi J, Pál A. Effect of body weight on testos- terone/estradiol ratio in oligozoospermic patients. Arch Androl 2006;52(2):97-102.

28. Martini AC, Tissera A, Estofán D, Molina RI, Mangeaud A, de Cuneo MF, et al. Overweight and seminal quality: a study of 794 patients. Fertil Steril 2010;94(5):1739-43.

29. Barnett R. Obesity. Lancet 2005;365(9474) 1843.

30. Aggerholm AS, Thulstrup AM, Toft G, Ramlau-Hansen $\mathrm{CH}$, Bonde JP. Is overweight a risk factor for reduced semen quality and altered serum sex hormone profile? Fertil Steril 2008;90(3):619-26.

31. Buiting $K$, Gross S, Lich C, Gillessen-Kaesbach G, el-Maarri O, Horsthemke B. Epimutations in Prader-Willi and Angelman syndromes: a molecular study of 136 patients with an imprinting defect. Am J Hum Genet 2003;72(3):571-7.

32. $\mathrm{NIH}$ Consensus Conference. Impotance. $\mathrm{NIH}$ consensus development panel on impotance. JAMA 1993;270(1):83-90.

33. Akkus E, Kadioglu A, Esen A, Doran S, Ergen $A$, Anafarta $K$, et al. Prevalence and correlates of erectile dysfunction in Turkey: a populationbased study. Eur Urol 2002;41(3):298-304.

34. Smith ML, Smith HA, Wilson KL, Ahn S, Pulczinski JC, Ory MG. Obesity and perceived severity of obstructive sleep apnea-related conditions. Fam Community Health 2014;37 (4):258-70

35. Janiszewski PM, Janssen I, Ross R. Abdominal obesity and physical inactivity are associated with erectile dysfunction independent of body mass index. J Sex Med 2009;6(7):19908.

36. Teitelman M, Grotegut CA, Williams NN, Lewis JD. The impact of bariatric surgery on menstrual patterns. Obes Surg 2006;16(11): 1457-63.

37. Brethauer SA, Chand B, Schauer PR. Risks and benefits of bariatric surgery: current evidence. Cleve Clin J Med 2006;73(11):9931007.

38. Yorke E, Switzer NJ, Reso A, Shi X, de Gara $C$, Birch D, et al. Intragastric balloon for management of severe obesity: a systematic review. Obes Surg 2016;26(9):2248-54.

39. González I, Rubio MA, Cordido F, Bretón I, Morales MJ, Vilarrasa N, et al. Maternal and perinatal outcomes after bariatric surgery: a Spanish multicenter study. Obes Surg 2015;25(3):436-42.

40. Musella M, Milone M, Bellini M, Sosa Fernandez LM, Leongito M, Milone F. Effect of bariatric surgery on obesity-related infertility. Surg Obes Relat Dis 2012;8(4):445-9. 
41. Milone M, De Placido G, Musella M, Sosa Fernandez LM, Sosa Fernandez LV, Campana $G$, et al. Incidence of successful pregnancy after weight loss interventions in infertile women: a systematic review and meta-analysis of the literature. Obes Surg 2016;26(2):443-51.

42. Kjær MM, Madsbad S, Hougaard DM, Cohen AS, Nilas $L$. The impact of gastric bypass surgery on sex hormones and menstrual cycles in premenopausal women. Gynecol Endocrinol 2017;33(2):160-3.

43. Adams TD, Hammoud AO, Davidson LE, Laferrère B, Fraser A, Stanford JB, et al. Maternal and neonatal outcomes for pregnancies before and after gastric bypass surgery. Int J Obes (Lond) 2015;39(4):686-94.

44. Maggard MA, Yermilov I, Li Z, Maglione M, Newberry S, Suttorp M, et al. Pregnancy and fertility following bariatric surgery: a systematic review. JAMA 2008;300(19):2286-96.

45. Marceau P, Kaufman D, Biron S, Hould FS, Lebel S, Marceau S, et al. Outcome of pregnancies after biliopancreatic diversion. Obes Surg 2004;14(3):318-24

46. Lesko J, Peaceman A. Pregnancy outcomes in women after bariatric surgery compared with obese and morbidly obese controls. Obstet Gynecol 2012;119(3):547-54 .
47. Aricha-Tamir B, Weintraub AY, Levi I, Sheiner E. Downsizing pregnancy complications: a study of paired pregnancy outcomes before and after bariatric surgery. Surg Obes Relat Dis 2012;8(4):434-9.

48. Rao RS, Yanagisawa R, Kini S. Insulin resistance and bariatric surgery. Obes Rev 2012;13(4):316-28.

49. Bebber FE, Rizzolli J, Casagrande DS, Rodrigues MT, Padoin AV, Mottin CC, et al. Pregnancy after bariatric surgery: 39 pregnancies follow-up in a multidisciplinary team. Obes Surg 2011;21(10):1546-51.

50. Robinson HE, O'Connell CM, Joseph KS, McLeod NL. Maternal outcomes in pregnancies complicated by obesity. Obstet Gynecol 2005;106(6):1357-64.

51. Goldman RH, Missmer SA, Robinson MK, Farland LV, Ginsburg ES. Reproductive outcomes differ following roux-en-Y gastric bypass and adjustable gastric band compared with those of an obese non-surgical group. Obes Surg 2016;26(11):25819.

52. Bastounis EA, Karayiannakis AJ, Syrigos K, Zbar A, Makri GG, Alexiou D. Sex hormone changes in morbidly obese patients after vertical banded gastroplasty. Eur Surg Res 1998;30(1):43-7.
53. El Bardisi H, Majzoub A, Arafa M, AlMalki A, Al Said S, Khalafalla K, et al. Effect of bariatric surgery on semen parameters and sex hormone concentrations: a prospective study. Reprod Biomed Online 2016;33(5):606-11.

54. Legro RS, Kunselman AR, Meadows JW, Kesner JS, Krieg EF, Rogers AM, et al. Timerelated increase in urinary testosterone levels and stable semen analysis parameters after bariatric surgery in men. Reprod Biomed Online 2015;30(2):150-6.

55. di Frega AS, Dale B, Di Matteo L, Wilding M. Secondary male factor infertility after Roux-en$Y$ gastric bypass for morbid obesity: case report. Hum Reprod 2005;20(4):997-8.

56. Chang SH, Stoll CR, Song J, Varela JE, Eagon CJ, Colditz GA. The effectiveness and risks of bariatric surgery: an updated systematic review and meta-analysis, 2003-2012. JAMA Surg 2014;149(3):275-87.

57. Sakran N, Goitein D, Raziel A, Keidar A, Beglaibter N, Grinbaum R, et al. Gastric leaks after sleeve gastrectomy: a multicenter experience with 2,834 patients. Surg Endosc 2013;27(1):240-5.

58. Birkmeyer NJ, Dimick JB, Share D, Hawasli A English WJ, Genaw J, et al; Michigan Bariatric Surgery Collaborative. Hospital complication rates with bariatric surgery in Michigan. JAMA 2010;304(4):435-42. 